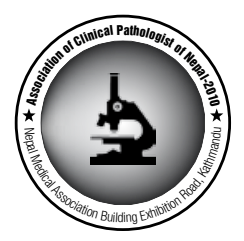

\title{
Adenomyoepithelioma of breast
}

\author{
Pradhan $\mathrm{S}^{1}$, Yadav RP ${ }^{2}$ \\ ${ }^{1}$ Department of Pathology, Advance Pathology Lab, Jhapa, Nepal \\ ${ }^{2}$ Department of Surgery, Om sai Pathibhara Hospital and Research centre, Jhapa, Nepal
}

\section{Keywords: \\ Adenomyoepithelioma; Myoepithelial cells}

\begin{abstract}
Adenomyoepithelioma is rare tumors of the breast. It is a benign tumor with balanced proliferation of both epithelial and myoepithelial cells. This benign tumor is known for its recurrences and metastatic potential. Hence accurate diagnosis with close follow up is mandatory. We present a case report on a young lady with adenomyoepithelioma who presented with well defined small nodules in her right breast.
\end{abstract}

\section{INTRODUCTION}

Myoepithelial cells are a normal component of breast tissue, and their presence in neoplastic lesions has been considered a hallmark of benignity. However several breast neoplasms entirely or partially composed of myoepithelial cells are recognized and grouped in three categories: myoepitheliosis, adenomyoepithelioma (AME) and myoepithelial carcinoma. ${ }^{1}$

AME is a rare tumor of breast and was first described by Hamperl in 1970s. ${ }^{2}$ They are characterized by biphasic proliferation of epithelial and myoepthelial cells. Although the majority of AME are benign, there are reports of local recurrences, metastasis and malignant transformation., ${ }^{1,-6}$ Failure to recognise this tumor may lead to inappropriate diagnosis and management. We report a case of AME with satellite lesion in a young female.

\section{CASE REPORT}

A 28-years-old female, presented with pain and lump in the

\section{Correspondence:}

Dr. Seema Verma Pradhan, $M D$

Consultant Pathologist

Advance Pathology Lab, Jhapa, Nepal

Email: pradhanseema30@yahoo.com right breast. Excision biopsy was done and two well-defined nodular swellings were removed. The clinical diagnosis was fibroadenoma. Gross examination showed two small nodular masses measuring $0.8 \times 0.8 \mathrm{~cm}$ and $0.5 \times 0.5 \mathrm{~cm}$ respectively. Cut section showed well defined mass with a yellowish surface (fig.1A \& 1B). The tissues were processed routinely in paraffin and Hematoxylin and Eosin (HE) stain was done.

Multiple HE sections taken from both the nodules showed well defined tumor. The smaller nodule showed a fibrous band all around the lesion. The tumor was composed of proliferating epithelial and myoepithelial cells (Fig. 2A $\&$ 2B). The epithelial cells formed round to elongated compressed tubules. A few of the tubules show luminal proteinaceous material and others were compressed with slit-like spaces lined by dual layer of epithelial and myoepithelial cells. The tubules were surrounded by proliferating myoepithelial cells with plasmacytoid and clear cells changes (Fig. 3A \& 3B). The lesion also showed focal hyalinisation, myxoid areas, and few cystic spaces with several mixed inflammatory cells. Atypia was absent and mitotic activity was expressed as $0-1 / 20$ HPF. The diagnosis of Adenomyoepithelioma was made and patient kept on follow up. 


\section{DISCUSSION}

Neoplasms of pure myoepithelial or mixed epithelial and myoepithelial origin are described in salivary glands but are very rare in breast. Myoepithelial lesions presents as a spectrum of myoepitheliosis, adenomyoepithelioma and myoepithelial carcinoma.

AME is defined as a biphasic epithelial/myoepithelial breast neoplasm with a clear expansion of the myoepithelial component. ${ }^{7}$ Majority of the cases of AME are reported in the fifth and sixth decade of life. It is uncommon in young patients but is occasionally seen in the third decade..$^{8,9}$ Our patient was a young female of 28 years. Rare cases of AME are seen in men. ${ }^{8}$

The AMEs presents as solid, well delineated rounded nodules varying from $0.3-7 \mathrm{~cm}$, often with a bossellated or multi-lobulated outline palpated clinically or discovered on imaging studies. Focal cystic degenrations may occur. Some are predominantly cystic, and some have a papillomatous component. Necrosis and calcification of the necrotic debris can occur. ${ }^{4,-12}$ Most are located centrally in the breast. Microscopic satellite nodules may occur at the periphery of the main tumour mass. ${ }^{13}$ Occasionally AME presents with pain or nipple discharge. Rarely AME arises within a fibroadenoma or phyllodes tumour., ${ }^{52} \mathrm{On}$ mammography AME usually forms a round or lobulated dense mass with margins that are partially indistinct but mostly circumscribed with or without calcification. On ultrasound examination are either solid, or have a combined solid and cystic appearance.

Histologically, AMEs is characterized by proliferation of layers of myoepithelial cells around epithelial lined spaces. The tubules are lined by cuboidal to columnar epithelial cells and are sometimes pushed to the edge of the nodule or may be compressed. Apocrine metaplasias are frequently noted. The myoepithelial component can be arranged from evenly

\section{Table 1. Classification of Myoepithelial lesions}

\begin{tabular}{ll}
\hline i. & Myoepitheliosis \\
& a. Intraductal \\
& b. Perductal \\
\hline ii. & Adenomyoepithelial Adenosis \\
\hline iii. & Adenomyoepithelioma \\
\hline & a. Benign \\
& b. With Malignant change (specify the type) \\
& i. Myoepithelial carcinoma arising in adenomyoepithelioma \\
& ii. Epithelil carcinoma arising in adenomyoepithelioma \\
& iii. Malignant epithelial and moepithelail component \\
& iv. Sarcoma arising in adenomyoepithelioma \\
& v. Carsinosarcoma arising in adenomyoepithelioma \\
\hline iv. & Malignant Myoepithelioma(ME carcinoma) \\
\hline
\end{tabular}

distributed to focal nests/nodules. The myoepithelial cells are usually polygonal with clear cytoplasm. Sometimes they are spindled or plasmacytoid. The benign AME is hence subdivided into spindle cell, tubular and lobulated types for benign tumors. In benign AME, both the components are cytologically bland with minimal pleomorphism and low mitotic rate generally $<2 / 10 \mathrm{HPF}$.

The myoepithelial cells are positive for glycogen, keratin and muscle markers. The myoepithelial cells may be highlighted by immunostains for p63 which stains the nuclei and cytoplasmic markers of myoid differentiation including actin, calponin and smooth muscle heavy chain myosin, but they are negative for H-caldesmon and desmin. The cytoplasm of the myoepithelial cells also stains for high molecular weight keratins CK5/6 and CK14 but is usually negative for low-molecular weight keratins CK8/18. They also stain with antibodies for S-100 protein, GFAP.4, 6, 13

Due to such varying degree of morphological variations, the tumor should be differentiated from papilloma with myoepithelial hyperplasia (myoepitheliosis), fibroadenoma, phyllodes tumour or tubular adenoma with AME-like areas, invasive ductal carcinoma, ductal adenoma and adenosis nodules.Papillomas with focal myoepithelial hyperplasia have focal myoepithelial cells unlike diffuse nature of AME. Some areas of AME may resemble adenoid cystic carcinoma of the breast but the latter neoplasm has infiltrative borders and a characteristic cribriform architecture in most cases; the myoepithelial cells of adenoid cystic carcinoma tend to be smaller, more hyperchromatic and basaloid appearing and have much less cytoplasm than those of AME. Myoepithelioma of the breast lacks the ductal component seen in AME. Pleomorphic adenoma of the breast shares with AME the dual epithelial and myoepithelial composition but has a more prominent myxochondroid matrix. Lowgrade adenosquamous carcinoma may enter the differential diagnosis on core biopsy, but this is an infiltrative neoplasm with an abundant desmoplastic stroma and the myoepithelial component is much less prominent than in AME. The ductal adenoma and adenosis are considered the other possible differential diagnosis. ${ }^{4,6,12}$

\section{MALIGNANT ADENOMYOEPITHLIOMA}

AME is usually slow growing neoplasms with a very low metastatic potential. However, AME has the potential for malignant progression. Malignant AME occurs more frequently in the $>60$ year age group and is often preceded by history of a longstanding stable mass followed by a period of rapid growth. However some malignant AMEs arise de novo in the absence of a precursor low-grade lesion. ${ }^{8}$

Grossly, these neoplasms are usually still partially well circumscribed but are infiltrative on microscopic examination. Cystic degeneration, calcification and necrosis are often seen. The malignant components may be either 

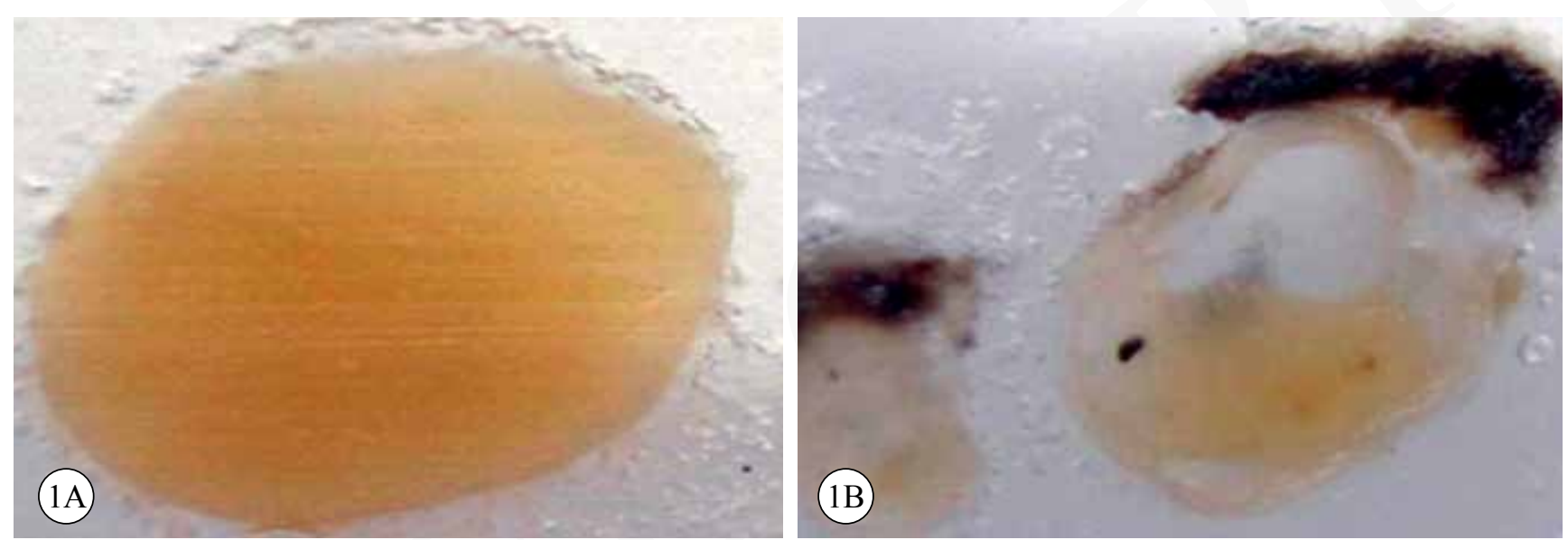

Figure 1A \& 1B: Gross picture showing well defined nodule with yellow white area.
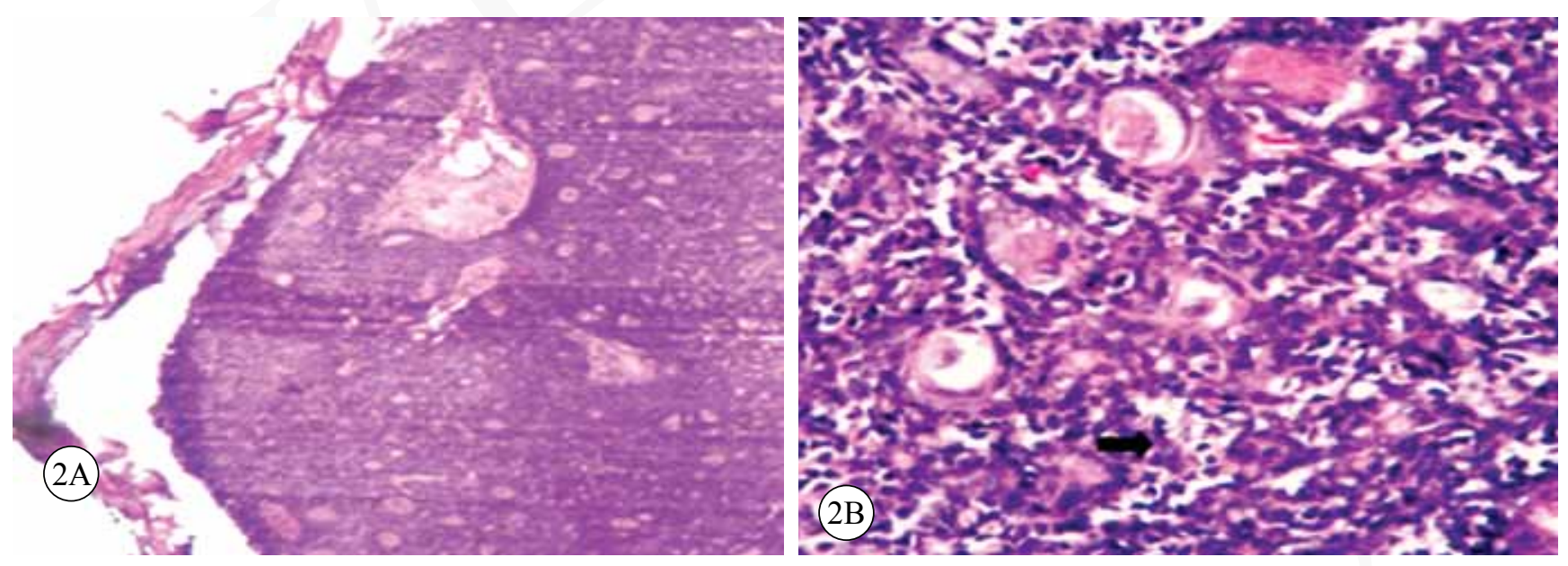

Figure 2A: A well defined tumor with tubules and solid area (HE stain, X50).

Figure 2B: Balanced proliferation of both epithelial and myoepithelial cells (arrowhead) (HE stain, X100)
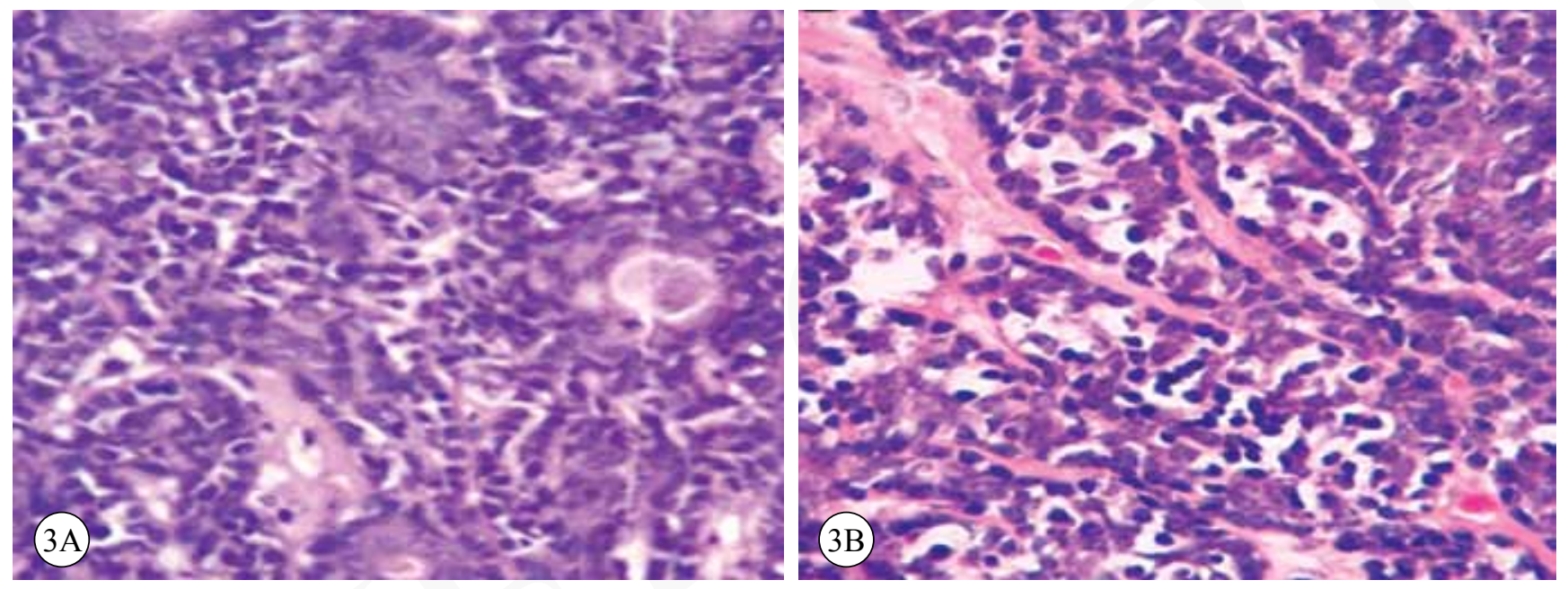

Figure 3A : Tubules surrounded by proliferating myoepithelial cells with plasmacytoid cells (HE stain, X400)

Figure 3B: Clear cell changes (HE stain, X1000) 
ductal, myoepithelial or both . Three malignancy predictors including high mitotic, rate, marked cytologic atypia, and infiltrative peripheral border have been proposed by Loose et $\mathrm{al}^{2}$ in their series of case studies. If the high-grade malignant component shows predominantly myoepithelial differentiation, identification of a low-grade component of $\mathrm{AME}$ is required in order to separate it from true malignant myoepithelioma. The classification of myoepithelial lesions are summarised in Table $1^{8,13,14}$.

AME is simply cured by complete excision with close follow-up. Our patient was treated with lumpectomy and was followed up for six months without any recurrence. Local recurrence may occur-possibly related to the multinodular growth and intraductal extension of the lesion to form satellite nodules away from the main tumour mass or incomplete excision. Malignant AME has greater potential to recur locally and has significant metastatic potentialprobably related to the grade of the malignant component. $\mathrm{Up}$ to $40 \%$ of malignant AME reported in the literature have metastasized. Most metastases involve the lungs, liver, bone, brain and other sites. There is little objective evidence to support a role for radiotherapy or chemotherapy in the management of AME. ${ }^{6-11,13,14}$

\section{CONCLUSION}

AME is a benign tumor of the breast with potential for recurrence metastasis and malignant transformation. It mimicks other benign and malignancy lesions of the breast in fine needle aspiration cytolology and hence poses a diagnostic challenge. True identification of the lesion helps for further management of the patient.

\section{REFERENCES}

1. Tavassoli FA. Myoepithelial lesions of the breast. Myoepitheliosis, Adenomyoepithelioma, and myoepithelial carcinoma. Am J Surg Pathol 1991;15:554-68.
2. Hamperl H. The myothelia (myoepithelial cells). Normal state; regressive changes; hyperplasia; tumors. Curr Top Pathol 1970;53:161-220.

3. Rosen PP. Adenomyoepithelioma of the breast. Hum Pathol $1987 ; 18: 1232-7$.

4. McLaren BK, Smith J, Schuyler PA, Dupont WD ,Page DL Adenomyoepithelioma: Clinical, Histologic, and Immunohistologic Evaluation of a Series of Related Lesions. Am J Surg Pathol 2005;29:1294-9.

5. Loose JH, Patchefsky AS, Hollander IJ, Lavin LS, Cooper HS, Katz SM: Adenomyoepithelioma of the breast.A spectrum of biologic behavior. Am J Surg Pathol 1992; 16:868-76.

6. Malcolm MH. Adenomyoepithelioma of the breast: a review stressing its propensity for malignant transformation J Clin Pathol 2011;64:477-84.

7. Jabi M, Dardick I, Cardigos N. Adenomyoepithelioma of the breast. Arch Pathol Lab Med 1988;112:73-6.

8. Tamura G, Monma N, Suzuki Y, et al. Adenomyoepithelioma (myoepithelioma) of the breast in a male. Hum Pathol 1993;24:67881.

9. Laforga JB, Aranda FI, Sevilla F. Adenomyoepithelioma of the breast: report of two cases with prominent cystic changes and intranuclear inclusions. Diagn Cytopathol 1998;19:55-8.

10. Papaevangelou A, Pougouras I, Liapi G, et al. Cystic adenomyoepithelioma of the breast. Breast 2004;13:356-8.

11. Catena F, Santini D, Di Saverio S, Ansaloni L, Taffurelli M. Adenomyoepithelioma of the Breast: An Intricate Diagnostic Problem Breast Care (Basel). Epub 2008;3:125-7.

12. Ahmed AA, Heller DS. Review malignant adenomyoepithelioma of the breast with malignant proliferation of epithelial and myoepithelial elements: a case report and review of the literature. Arch Pathol Lab Med. 2000;124:632-6.

13. Tavassoli F, Soares J. Myoepithelial lesions . In: Tavassoli FA, Stratton MR, editors. WHO Classification of Tumors: Pathology and Genetics, Tumors of the Breast and Female Genital Organs. Lyon: IARC, 2003.pp86-7

14. Kihara M, Yokomise H, Irie A, Kobayashi S, Kushida Y, Yamauchi A; .Review malignant adenomyoepithelioma of the breast with lung metastases: report of a case. Surg Today. 2001;31:899-903. 